\title{
Impactos da COVID-19 na vida das mulheres em Portugal: Breve análise temática
}

\begin{abstract}
Fernanda Lyrio Heinzelmann', Lina Coelho', Mónica Lópes $^{1}$ e Cristina C. Vieira ${ }^{2}$

${ }^{1}$ Centro de Estudos Sociais (CES), Portugal | fernandalyrio@ces.uc.pt; Icoelho@fe.uc.pt; monica@ces.uc.pt | https://orcid.org/0000-0001-79814127; https://orcid.org/0000-0002-8641-417X; https://orcid.org/0000-0001$7892-8560$

${ }^{2}$ Centro de Investigação em Educação de Adultos e Intervenção Comunitária da Universidade do Algarve (CEAD), Portugal | vieira@ces.uc.pt | https://orcid.org/0000-00029814-1076

Resumo: O agravamento das desigualdades de género devido à pandemia de COVID-19 motiva o presente artigo. $O$ estudo aqui descrito se insere numa investigação maior, cujo objetivo é conhecer os impactos da crise na vida das mulheres e suas famílias, em termos de emprego, rendimento e condições de vida. O método utilizado foi a análise temática de caráter indutivo, aplicada a respostas dadas por 334 mulheres residentes em Portugal a duas perguntas de resposta aberta presentes no inquérito da investigação, ainda em curso, sobre os impactos da pandemia. As respostas foram coletadas entre outubro de 2020 e janeiro de 2021. Identificaram-se oito categorias de análise - teletrabalho, regresso ao trabalho, trabalho não-remunerado, falta, casa, confinamento, adoecimento e saúde mental associadas a três grandes temas que orientam o estudo: trabalho, rendimento e condições de vida. São temas e categorias de análise interligados, que apresentam um quadro geral sobre a situação das mulheres neste período. No geral, percebeu-se um esgotamento financeiro, físico e mental feminino que se relaciona com todas as áreas abordadas. A incerteza geral sobre o futuro surge como fator de agravamento desta situação. Trata-se de um contexto que sobrecarrega muito as mulheres, apontando para a necessidade de maior atenção à população feminina nas políticas de combate à pandemia e às suas consequências sociais e económicas.
\end{abstract}

Palavras-chave: COVID-19; Mulheres; Desigualdades de Género; Condições de Vida.

\section{COVID-19 Impacts for Portuguese Women's Lives: A Brief Thematic Analysis}

Abstract: Further knowledge on the worsening of gender disparities due to the COVID-19 pandemic motivated this article. The brief study described is part of a larger investigation aiming to find out how the crisis impacts the lives of women and their families, in terms of employment, income and living conditions. The method used is a thematic analysis of an inductive approach applied to responses given by 334 women, residing in Portugal, to two open-ended questions included in the major research survey, still ongoing. Responses were collected between October 2020 and January 2021. Eight categories of analysis were identified: home office, return to work, unpaid work, lack, home, confinement, illness, and mental health. Those were associated with three major themes that guide the study: work, income and living conditions. The themes and analysis' categories are interlinked and present a general picture of the actual situation of women. In general, it was noticed financial, physical and mental exhaustion of women relating to all the areas addressed. Worldwide uncertainty about the future seems to aggravate the situation. That is a situation overburdening women, which requires greater attention to the female population by the policies adopted to fight both the pandemic and its social and economic consequences.

Keywords: COVID-19; Women; Gender Inequalities; Living Conditions.

\section{Introdução}

Um ano após o início da pandemia, a noção inicial de que o vírus seria "democrático" se provou falsa, pois a COVID-19 parece, afinal, ter revelado e intensificado desigualdades sociais pré-existentes. Grupos sociais desfavorecidos viram sua situação mais agravada (Silva et al., 2020; EIGE, 2020; Lusa, 2020; Católica-Lisbon, 2020). 
O objetivo da nossa investigação é conhecer os impactos da crise na vida das mulheres e suas famílias, em termos de emprego, rendimento e condições de vida. A revisão da literatura sobre a pandemia, a crise gerada pela mesma e seus efeitos sobre desigualdades de género apoiou-se numa busca não sistemática em bases de dados de publicações científicas, imprensa e relatórios de pesquisa (Kim \& Patterson, 2020; Yildirim \& Eslen-Ziya, 2020; Del Boca et al., 2020). Foram considerados temas de interesse: crise, desigualdades de género, efeitos no trabalho, remunerado e não remunerado, situação económica, relações familiares e saúde mental.

A literatura mostra que as crises económicas tendem a ser mais gravosas para as mulheres do que para os homens (Elson, 2013; Gálvez-Muñoz \& Rodríguez-Modroño, 2012; Karamessini \& Rubery 2013; Coelho, 2016). Em contextos de crise, elas são penalizadas pelas caraterísticas gerais da sua participação no mercado de trabalho: maior precariedade, maior incidência de horários a tempo parcial, profissões e atividades mais mal remuneradas. Ainda, em situação de retração do rendimento familiar, ou dos serviços públicos de apoio, são elas, sobretudo, quem suporta a sobrecarga adicional de trabalho doméstico e familiar. E, consequentemente, sofrem redução de disponibilidade para dedicação à carreira.

A presente crise constitui uma ameaça particularmente deletéria para as mulheres (Coelho, 2020), sobretudo devido à segregação sexual do emprego prevalecente (Coelho \& Ferreira, 2018). As mulheres constituem a maioria das pessoas que trabalham na chamada 'linha da frente' (saúde, cuidado a idosos e pessoas vulneráveis, retalho alimentar, limpezas), o que as expõe a um risco acrescido de contágio. Estão em maioria em setores obrigados à inatividade para garantir distanciamento social (beleza e bemestar, comércio a retalho, hotelaria e restauração), o que implica perdas de rendimento e/ou de emprego. Quando em teletrabalho enfrentam, em muitos casos, a necessidade de assegurar, no espaço doméstico, o exercício da atividade profissional, o apoio à escola online dos filhos e/ou o cuidado a pessoas dependentes, e a intensificação das habituais tarefas familiares (Coelho, 2020).

\section{Metodologia}

Os dados foram obtidos através de um inquérito direcionado a mulheres maiores de 18 anos, residentes em Portugal, disponibilizado online e divulgado através de listas de contactos de instituições diversas e via Facebook. Decorreu entre Outubro de 2020 e Maio de 2021. Os dados aqui analisados referem-se às respostas obtidas até 14 de Janeiro de 2021, início do segundo confinamento geral em Portugal. Embora a maioria das perguntas que constituem o questionário sejam de resposta fechada (45), no final incluiram-se duas respostas abertas que possibilitam análise qualitativa: "Desde o início da pandemia até agora qual foi o período/momento mais crítico para si?" e "Porquê?".

A amostra abrange 334 mulheres, cuja idade média é 42 anos, sendo que $38(11,4 \%)$ têm menos de 25 anos, 291 (87,1\%) entre 25 e 64 anos, e as restantes 65 anos ou mais. A dimensão média dos respetivos agregados familiares é 2,8 pessoas. Relativamente à situação conjugal, 189 viviam em casal. Das restantes, 98 são solteiras, 43 divorciadas e 4 viúvas. Entre as primeiras, 126 coabitava com filhos, algo que acontecia também com 27 divorciadas, 11 solteiras e 3 viúvas. Relativamente à escolaridade, 72 têm diploma de doutoramento, 221 licenciatura/mestrado; 36 diploma secundário ou pós-secundário não superior e 5 inferior. A maioria estava empregada (86,2\%), 28 eram estudantes, 14 desempregadas, 2 reformadas e uma doméstica. Entre as empregadas, 265 trabalhavam por conta de outrem, 13 por conta própria, 10 eram bolseiras de investigação. Em 46 casos trabalhavam para empresas privadas, em 166, para setor público, e em 49, instituições sem fins lucrativos. Entre as profissões destacam-se docentes (66), técnicas superiores em funções públicas (42) e investigadoras (35), representando, no conjunto, quase metade do emprego. No total, 231 inquiridas estiveram em teletrabalho durante 0 primeiro confinamento, e 30 no local de trabalho habitual. 
Para análise dos dados obtidos nas perguntas supracitadas usamos Análise Temática, a fim de "identificar, analisar e reportar padrões (temas) nestes dados" [tradução nossa] (Braun \& Clarke, 2006, p.6). Este método tem caráter essencialmente qualitativo, permitindo flexibilidade e ampla gama de possibilidades analíticas, seja análise indutiva, focada em dados, ou análise dedutiva, de matriz mais teórica. A análise temática compreende seis etapas (Braun \& Clarke, 2006): familiarização com os dados; codificação; busca por temas; revisão dos temas; definição e nomeação dos temas; e produção do relatório.

As respostas às perguntas foram lidas e relidas reiteradamente, considerando a revisão literária, para permitir a formulação de ideias iniciais. Optamos pela análise temática indutiva: "um processo de codificação dos dados, sem tentar encaixá-los em um quadro de codificação preexistente, ou nos preconceitos analíticos do pesquisador. Neste sentido, esta forma da análise temática é guiada pelos dados" [tradução nossa] (ibidem, p.14). Esta escolha alinha-se ao objetivo geral da investigação: conhecer de que forma a vida das mulheres e suas famílias estão a ser atingidas pela crise em termos de emprego, rendimento e condições de vida.

Assuntos centrais da investigação - trabalho, rendimento e condições de vida orientaram a geração de códigos iniciais, selecionando extratos do banco de dados que pareciam relevantes e relacionados àqueles assuntos. As respostas às perguntas foram listadas separadamente, e posteriormente codificadas. As perguntas, embora separadas no inquérito, estão diretamente relacionadas, pois a pergunta "porquê" deriva da pergunta anterior.

$\mathrm{Na}$ terceira etapa, os códigos foram relidos e reunidos em temas e subtemas potenciais. Identificámos temas relacionados com a investigação, centrando a atenção na identificação de ideias em destaque nas respostas das participantes. Ainda que as escolhas tenham sido feitas em virtude dos códigos previamente elencados, tentamos evitar a organização dentro de temas e subtemas de forma rígida. O critério para a categorização procurou seguir pontos característicos de cada tema e subtema em função do que havia de mais relevante no trecho selecionado.

$\mathrm{Na}$ etapa de revisão e refinamento dos temas, os extratos foram novamente lidos em busca de um padrão. Chegamos a três grandes temas e oito subtemas, dos quais ainda derivaram dez subtemas em um dos temas. As respostas foram divididas entre estes temas e subtemas, gerando o mapa temático da análise (Figura 1). Com base neste mapa, foram definidas especificidades de cada tema, e estes analisados e nomeados em definitivo. Isto possibilitou ter uma ideia da história geral contada pelos temas, tendo como base a revisão da literatura.

Finalmente, foram destacados extratos relevantes de cada tema que melhor representam as ideias centrais nele contidas, tendo em conta os objetivos da investigação. Estes extratos serão expostos e discutidos na seção seguinte. As ideias derivadas dos temas aparecem na seção final do texto.

\section{Resultados}

Identificaram-se oito categorias de análise, associadas aos três grandes temas que guiam nosso estudo: trabalho, rendimento e condições de vida. Apesar da diversidade de menções, os temas foram organizados em função da densidade e relevância dos seus conteúdos. 

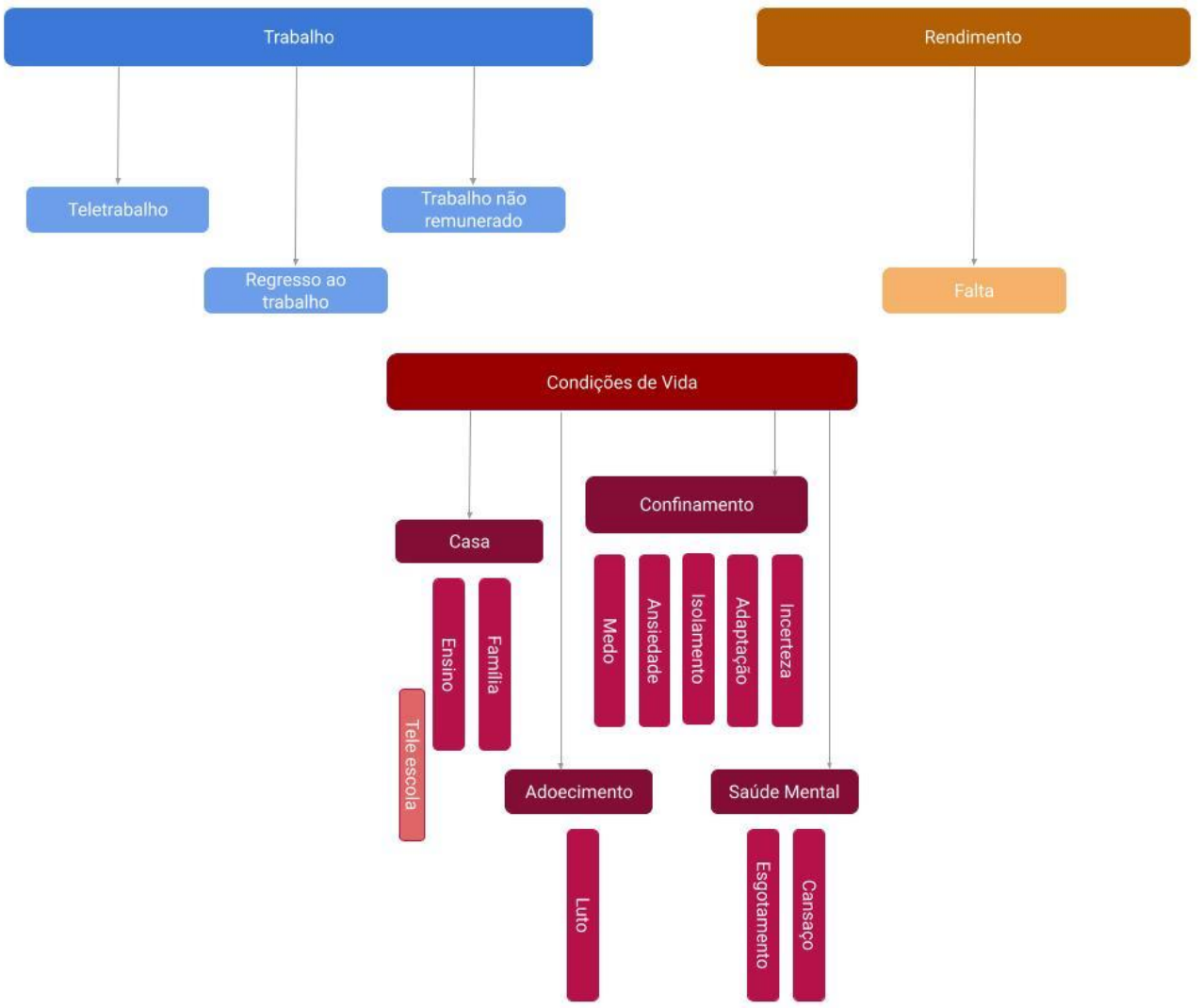

Fig. 1. Mapa temático da análise.

\subsection{Trabalho}

O tema trabalho contemplou três subtemas: teletrabalho, trabalho presencial e trabalho não remunerado. Nele foram listadas as respostas relacionadas aos obstáculos relatados pelas participantes quanto à adaptação das tarefas laborais na pandemia. Um ponto relevante, seja no trabalho presencial, pela dificuldade de executá-las presencialmente com segurança, seja em teletrabalho, por dividir o mesmo ambiente com cônjuges e/ou filhos/as. Tarefas domésticas também foram apontadas como fator de constrangimento à execução das tarefas profissionais. E foram ainda mencionadas como vetor de conflitos no agregado familiar, dada a carga de trabalho excedente para as mulheres.

Uma participante cita sobrecarga de trabalho, mas também exigência emocional na adaptação ao trabalho: "Necessidade constante de ter que tomar decisões de trabalho, acumular de trabalho, incertezas a cada semana no trabalho, excesso de trabalho, não ter tido umas férias para relaxar e sair de casa", refere sobre o período entre Abril e Julho de 2020. Relatos ligados ao tema trabalho alinham-se a esta percepção e dão indícios da exaustão feminina acentuada pela pandemia.

Quem esteve em trabalho presencial também vivenciou dificuldades. Uma participante afirmou que o regresso ao trabalho presencial foi o momento mais crítico para si, "pela falta de respeito e cumprimento das regras pelos clientes". Contato obrigatório com colegas, ou com público, foram motivos de preocupação para algumas mulheres. Importa lembrar que muitos postos de trabalho ocupados pelas mulheres têm caráter presencial: áreas de serviços e cuidados (EIGE, 2020; Lusa, 2020; Católica-Lisbon, 2020).

Apesar do caráter qualitativo desta análise, parece relevante que o subtema "trabalho não remunerado" tenha listado o maior número de extratos. Trata-se de pautas feministas históricas, já que tais tarefas são percebidas como responsabilidade das mulheres (Federici, 1975). 
Foi mencionada a gama de tarefas e o impacto da disparidade na distribuição destas, não apenas na produtividade do trabalho, mas na organização pessoal e qualidade de vida das mulheres.

Uma participante refere abril e maio de 2020 como mais críticos, "devido ao confinamento com toda a família em casa e necessidade de acumular teletrabalho, assistência aos filhos e tarefas domésticas a redobrar". Este fardo que as mulheres carregam, em especial as mães, tem impactos diretos na quantidade de horas diárias trabalhadas e nas mudanças e adaptações ligadas à rotina de trabalho. Por isso, foram as mães que muito mais frequentemente cortaram horas da jornada de trabalho remunerado, ou abriram mão de seus empregos (Kim e Patterson, 2020; Yildirim, e Eslen-Ziya, 2020). Segundo Del Boca et al., 2020, parceiros homens não só mantiveram a carga de trabalho anterior à pandemia, como ainda puderam passar mais tempo de qualidade com as crianças, num trabalho familiar visto como mais gratificante que os cuidados com a casa.

\subsection{Rendimento}

Embora este tema tenha o menor número de extratos listados, gerando um único subtema, foi mantido pela sua relevância no contexto da investigação, bem como pela profundidade presente nos extratos associados. Nele revelam-se dificuldades financeiras enfrentadas pelas mulheres, mas também a carga emocional negativa resultante da quebra no orçamento: "tive de mudar de casa, estou sem dinheiro, a receber apoio alimentar".

A Organização Internacional do Trabalho refere que, na Europa, os salários das mulheres foram os mais afetados, pela perda de emprego ou redução de horas de trabalho. Portugal foi o país europeu onde os salários mais recuaram (13.5\% na primeira metade de 2020) sobretudo para as mulheres: perdas de $16 \%$, em relação a $11,4 \%$ nos salários dos homens (ILO, 2020; Martins, 2020). Sabe-se também que dos 200.649 trabalhadores portugueses que solicitaram subsídio emergencial para cuidar dos filhos em casa, $81 \%$ eram mulheres (Flor e Neves, 2020).

O subtema "falta" representa este contexto de escassez, referido em estudos anteriores e relatado pelas participantes. Extratos deste subtema passam pela ausência de emprego, falta de dinheiro, e dificuldade de adquirir bens alimentares, materiais de proteção e até de acesso à moradia. Faltas que causam sensação e percepção da precariedade, como aponta uma participante: "nesses meses entrei em espiral devido à falta de rendimentos e a necessidade de conciliar um trabalho com estudo e com condições dignas".

\subsection{Condições de Vida}

Este foi o tema mais frequente em subtemas e extratos associados, também por incluir uma maior gama de assuntos e por se relacionar a conceitos já expressos nos outros temas. Identificámos quatro subtemas: casa, confinamento, adoecimento e saúde mental. Apercebem-se dinâmicas ligadas à vida familiar, compartilhamento da casa, e conflitos derivados mas, também, os efeitos de dúvidas, incertezas e adaptações. E ainda consequências físicas e mentais para as mulheres de problemas de saúde, relacionados, ou não, com a pandemia.

O confinamento total entre março e maio de $2020 \mathrm{fez}$ disparar inquietações. Muitas pessoas ficaram desempregadas e o tempo "livre" permitiu maior consumo de informações sobre a COVID-19. Já em 2020, um estudo apontou que esta situação provocou aumento de ansiedade, stress e depressão (Morgado, 2020). Extratos das respostas das participantes mencionam reiteradamente ansiedade e medo: "Sensação de estar presa, de não controlar a minha saúde e dos meus entes queridos. Medo da doença". 
Uma participante destacou a "impossibilidade de sair de casa, preocupação com emergências variadas". O anúncio do Estado de Emergência e consequente confinamento suscitou muitas dúvidas sobre medidas de segurança frente ao vírus e sobre a duração da pandemia. Outra inquirida refere "dúvidas relativamente ao tempo que iria durar aquele período e pela dificuldade de conciliar a vida profissional com a vida familiar quando temos duas crianças menores de 13 anos".

Cansaço e esgotamento foram conceitos associados ao confinamento, um período crítico para muitas inquiridas. O prolongamento da pandemia também suscita estas sensações: "Tenho ideia que o cansaço me apanhou. Quase como se estivesse numa corrida que nunca mais acaba e não sabes se vais ter energia para a terminar". O adoecimento e eventual luto por familiares também tiveram menções como fatores de deterioração da saúde mental: "De ressalvar que a alteração da rotina de trabalho influenciou psicologicamente o processo de luto, uma vez que o teletrabalho promoveu um maior isolamento", afirmou uma das respostas.

Finalmente, a negociação sobre divisão do espaço da casa, devido ao confinamento ou pelo teletrabalho e ensino à distância, é também listada como causadora de conflitos. Desde uma piora na qualidade das relações familiares, até ao término de relacionamentos e divórcios, como confirmado pelo aumento no número de divórcios no terceiro trimestre de 2020, em relação ao mesmo período de 2019 (Faria, 2020). Uma tendência também apontada pelo inquérito da CESOP-Católica-Lisbon (2020): 10\% dos participantes apontou o divórcio como um dos acontecimentos prováveis nos próximos tempos. Um dos extratos resumiu: "a relação conjugal deteriorou-se".

\section{Conclusões e Considerações Finais}

Os resultados resumem brevemente os efeitos do primeiro ano da pandemia na vida das mulheres em Portugal. A análise procurou não compartimentar as questões abordadas, focando atenção nas situações relatadas pelas mulheres. Para melhor explanação dos conceitos trabalhados, expusemos estes dados preliminares alinhados aos temas que surgiram na análise. Trata-se de temas e subtemas interligados, com questões conectadas entre si.

A adaptação da vida familiar ao contexto da pandemia faz sobressair o acúmulo de trabalho não remunerado. Da mesma maneira, ao abordar a quebra de rendimentos das mulheres, precisamos considerar disparidades históricas entre homens e mulheres.

Percebeu-se um esgotamento financeiro, físico e mental feminino. A incerteza sobre o futuro vivida mundialmente parece agravar esta situação. Após um ano, ainda não é possível traçar um plano concreto para combater tal esgotamento. Trata-se de um contexto problemático, com grande sobrecarga sobre as mulheres. E, portanto, estas devem ser mais consideradas e melhor atendidas pelas políticas de combate à pandemia e suas consequências sociais e económicas.

Esta análise qualitativa constitui a etapa inicial de uma investigação de caráter misto cujos próximos passos incluem a análise do corpus dos dados obtidos. Após triangulação de dados, esperamos poder aprofundar as contribuições da investigação para os métodos qualitativos. A etapa futura incluirá as respostas coletadas a partir de 15 de Janeiro de 2021, quando Portugal entrou novamente em confinamento. 


\section{Referências ${ }^{1}$}

Braun, Virginia, \& Clarke, Victoria. (2006). Using thematic analysis in psychology, Qualitative Research in Psychology, 3:2, 77-101, DOI: 10.1191/1478088706qp063oa

Católica-Lisbon (2020). 2020: A Odisseia da Economia Portuguesa no Grande Confinamento. NECEP - Núcleo de Estudos de Conjuntura para a Economia Portuguesa (Católica-Lisbon Forecasting Lab). Católica Lisbon School of Business \& Economics. Lisboa.

Coelho, Lina. (2020). Desigualdades em tempos de pandemia: o (des)cuidado que nos ameaça. In A. Garrido \& H. Costa (Eds.), Um Vírus que nos Reúne. Reflexões da FEUC (pp. 45-50). Porto: Grupo Editorial Vida Económica.

Coelho, Lina. (2016). Finanças conjugais, desigualdades de género e bem-estar: facetas de um Portugal em crise. Revista Crítica de Ciências Sociais, (111), 59-80

Coelho, Lina, \& Ferreira, Virgínia. (2018). Segregação sexual do emprego em Portugal no último quarto de século-Agravamento ou abrandamento?. e-cadernos CES, (29).

Del Boca, Daniela; Oggero, Noemi; Profeta, Paola; Rossi, Maria Cristina. (2020). Women's Work, Housework and Childcare, before and during COVID-19. IZA DP No. 13409. Bonn.

EIGE (2021). Gender inequalities in care and consequences for the labour market. Luxembourg: Publications Office of the European Union. doi:10.2839/074.

Elson Diane. (2013). Economic crises from the 1980s to the 2010s: a gender analysis. In S.M. Rai \& G. Waylen (Eds.), New Frontiers in Feminist Political Economy. London: Routledge.

Faria, Natália. (2021). A crise de saúde mental está instalada. Ignorá-la será um erro "de dimensões catastróficas". Jornal Público, 04 de Fevereiro de 2021.

Federici, Silvia. (1975). Wages against Housework. London: Power of Women Collective, Print.

Flor, Aline; Neves, Sofia. (2020). Em cada cinco pedidos de apoio excepcional à família, quatro são de mulheres. Jornal Público.

Gálvez-Muñoz, Lina, \& Rodríguez-Modroño, Paula. (2012). La desigualdad de género en las crisis económicas. Investigaciones Feministas, 2, 113-132.

DOI : 10.5209/rev_INFE.2011.v2.38607

International Labour Organization - ILO. (2020). Global Wage Report 2020-21: Wages and minimum wages in the time of COVID-19. International Labour Office - Geneva: ILO, 2020.

Karamessini, Maria, \& Rubery, Jill. (2013). Women and Austerity - The Economic Crisis and the Future for Gender Equality. London: Routledge.

Kim, Eunji, \& Patterson, Shawn. (2020). The Pandemic and Gender Inequality in Academia (July 20, 2020). Available at SSRN: https://ssrn.com/abstract $=3666587$ or http://dx.doi.org/10.2139/ssrn.3666587

Lusa (2020). Mulheres são mais afectadas pela pandemia, alerta Comissão para a lgualdade. Jornal Público.

Martins, Raquel. (2020). Salários das mulheres em Portugal foram os mais penalizados pela pandemia. Jornal Público, 02 de Dezembro de 2020.

Morgado, Pedro. (2020). Saúde mental em tempos de pandemia COVID-19: uma perspetiva da Medicina.

Silva, Pedro Adão e, Carmo, Renato Miguel, Cantante, Frederico, Cruz, Catarina, Estêvão, Pedro, Manso, Luís, Pereira, Tiago Santos. (2020). Trabalho e desigualdades no Grande Confinamento. (Estudos CoLABOR, N.ㄹ 2/2020). CoLABOR.

Yildirim, T. Murat; Eslen-Ziya, H (2020). The differential impact of COVID-19 on the work conditions of women and men academics during the lockdown. Gender Work Organ. 2020; 17. https://doi.org/10.1111/gwao.12529

\footnotetext{
${ }^{1}$ A organização das referências bibliográficas obedeceu às regras estipuladas pela APA (American Psychological Association), ressalva-se, no entanto, a opção das investigadoras em registar os nomes próprios por extenso.
} 